Please send trade news information and illustrations to Arveen Bajaj at the $B D J$, Nature Publishing Group, The Macmillan Building, 4-6 Crinan Street, London N1 9XW.

Trade news is provided as a service to readers using text and images from the manufacturer, supplier or distributor and does not imply endorsement by the $B D J$. Normal and prudent research should be exercised before purchase or use of any product mentioned.

\section{Orally administered tablet}

Periostat is an orally administered tablet to be taken twice daily, and can be an effective adjunctive treatment to scaling, root planing and deep cleaning of the teeth and gums. It also promotes attachment level gain and reduces pocket depth in patients with adult periodontitis. Current treatments for periodontitis address the bacterial component of the gum disease while Periostat treatment is designed to reduce the activity of the enzymes that destroy tooth and gum tissue. The product offers the additional advantage of simultaneously treating every site. It is available from Alliance Pharmaceuticals Ltd.

Reader response number 50

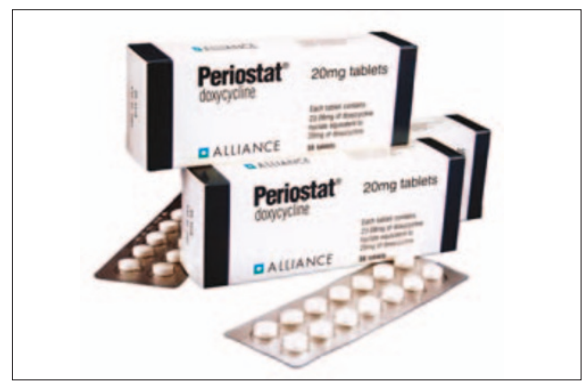

\section{Reducing hand bacteria}

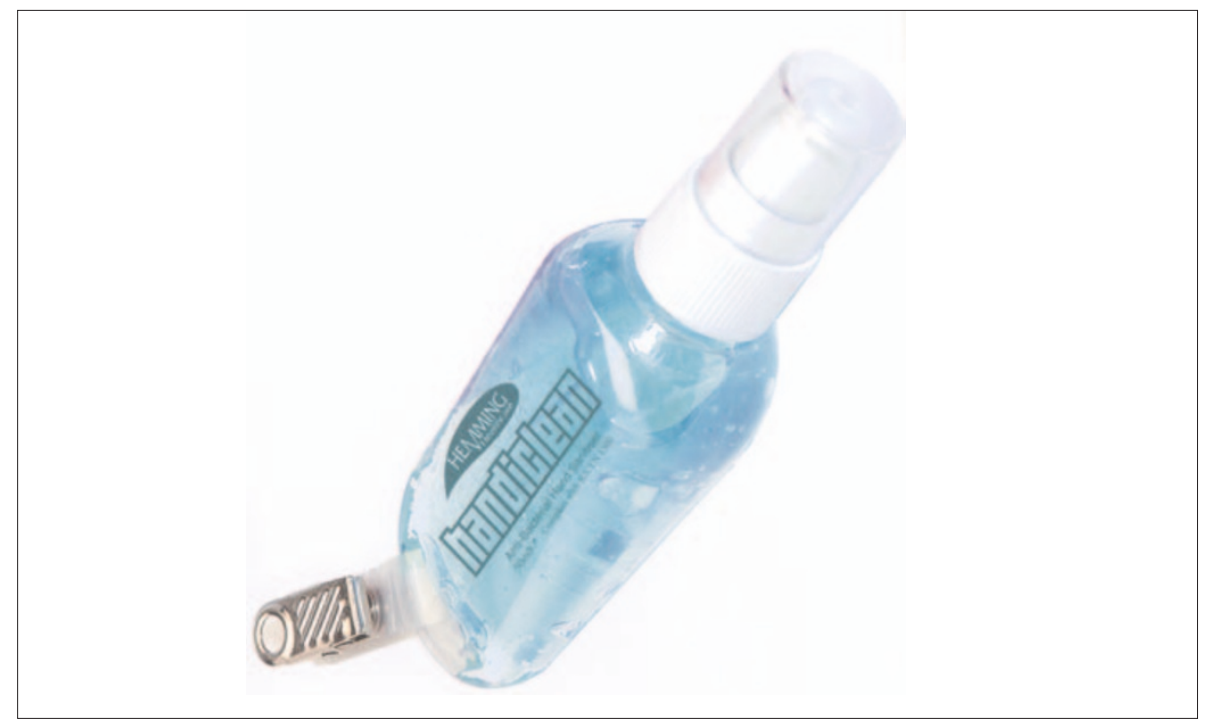

New Handiclean gel can help prevent the spread of invisible bacteria, viruses, microbes and superbugs and avoid cross contamination. After washing, hands can become become re-contaminated from taps and sinks, dryers or towels. By using Handiclean, an alcohol 'waterless' hand sanitiser, cross contamination can be avoided.

Regular use can help reduce hand bacteria as alcohol kills rather than removes microorganisms. The product is offered in $250 \mathrm{ml}$ dispensers designed for surgery, bathroom and reception, and handy 50ml 'clip-ons' designed for professionals on the move. Contact www.hemmingva.com for details.

Reader response number 51

\section{Diverse storage solutions}

The wide range of storing and filing options now available from Admor can provide practices with durable products for storage and filing needs. The company have introduced new ranges of Fleximetric, Metro and Easy File filing cabinets. Fleximetric high density record card storage systems offer extra deep drawers for added capacity, whilst saving on the floor space currently used for filing. All units are free standing and include anti-tilt mechanisms for compliance with health and safety regulations. They are lockable for security, helping to ensure patient confidentiality, and come with a seven year manufacturer warranty for your peace of mind.

Metro high density shelved units are designed to accommodate dental records in fibreboard boxes and store a similar volume of records at a reduced cost per record. The shelving system is easy to move if a new layout is required and it can be converted to A4 filing if requirements change. Lastly, Easy File filing cabinets have been recently introduced to the Admor range as a solution to office admin filing requirements. Reader response number 52

\section{Ergonomical comfort}

Midmark has launched a new, thin and narrow back for its dental chair called the Ultratrim. This chair extends Midmark's current dental product line, which also includes the UltraComfort chair back. The new back is designed to accommodate clinicians who prefer direct access to the oral cavity when approaching the patient from the nine o'clock position without sacrificing the patient's comfort. The back is also designed for dental hygienists who move around the patient's head as they operate. Patient access and comfort is enhanced by the patented integrated arm rests, advanced lumbar design and sculpted seat and back that securely supports the patient for comfort in all positions. It is available in many operatory configurations complete with advanced lighting solutions, instrument packages and a comprehensive range of other components. Both the UltraComfort and UltraTrim chair backs are interchangeable and available in a variety of upholstery, colours and headrests.

Reader response number 53

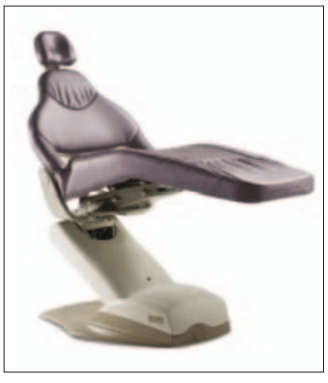



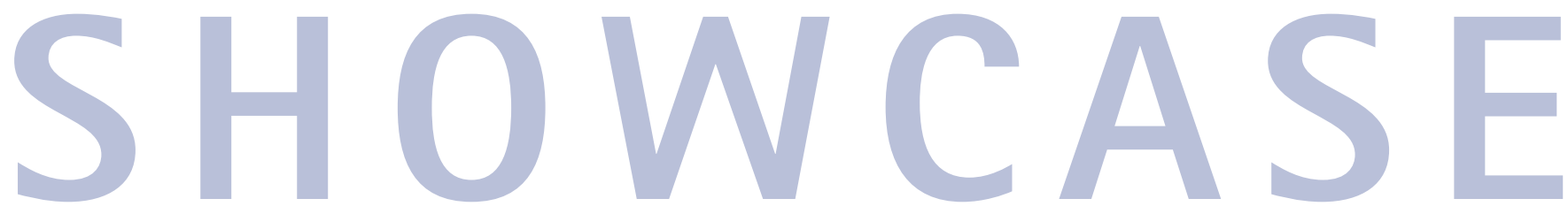

\section{Swiss technology}

Visitors to the Bien-Air stand (B02) can see product demonstrations and receive special introductory prices on products including handpieces. On display will be the Bien-Air Optima MX for restoration, endodontics, caries removal and prophylaxis work. It features torque control, auto forward/reverse and a colour touch-screen and there are value packages for straightforward 'add-on's' to existing units.

For the laboratory, visitors can come and try the new Prolab with integral motor/handpiece or MX Brushless 'E' fitting motor for which there is a show offer available. A prize draw will also take place on the stand.

Reader response number 54

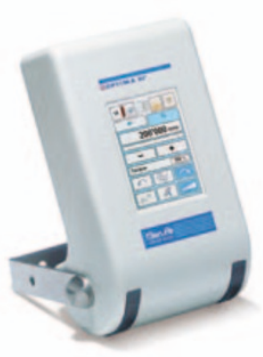

\section{Anniversary celebrations}

A-dec UK will be celebrating its 20-year anniversary on stand G03 this year.

The company will be exhibiting the Adec 500 and Radius units, and unveiling some important new additions to the A-dec product range. It designs, builds, and markets equipment including chairs, stools, delivery systems, dental lights, and a full line of accessories.

Reader response number 55

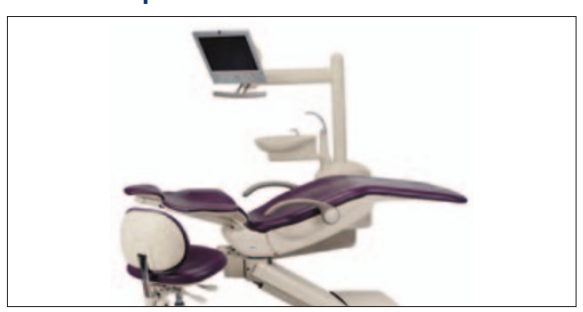

\section{Latest dental equipment}

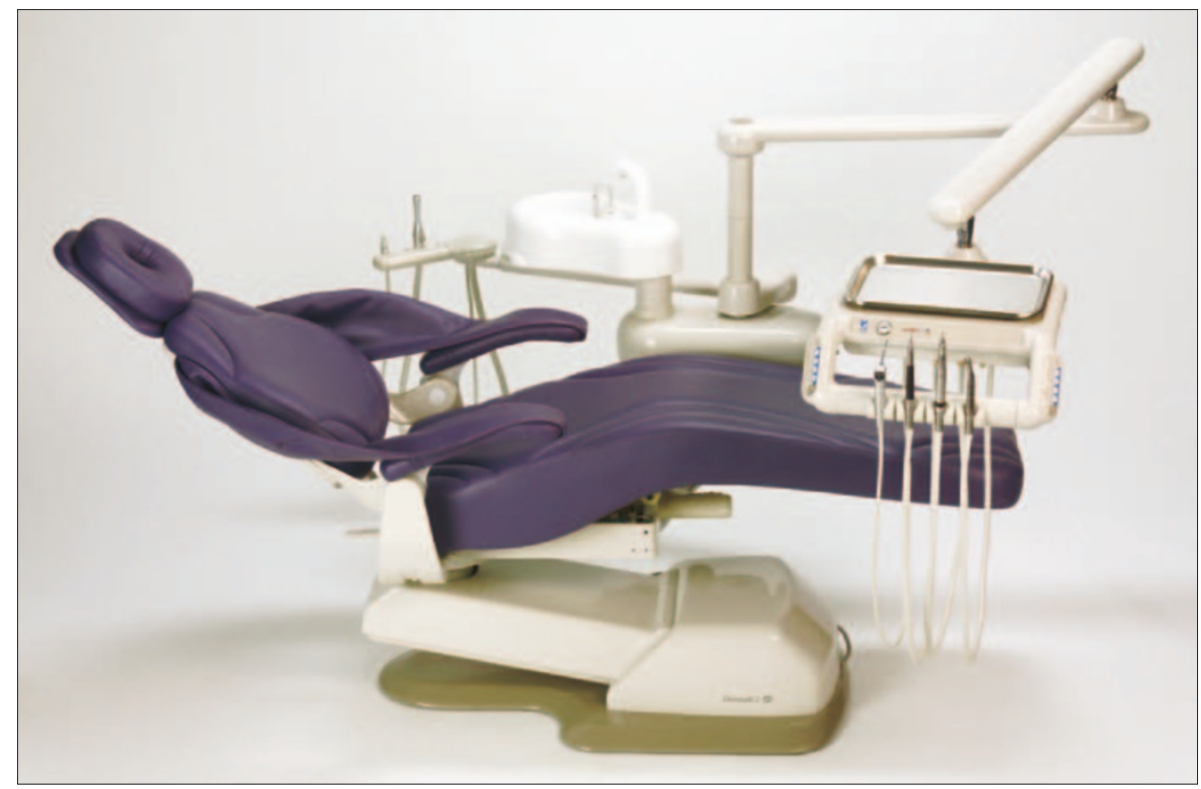

The latest in dental equipment from DentalEZ can be seen on stand B12 at this years Showcase exhibition. DentalEZ supply a wide range of equipment including chairs, units, lights, vacuum, handpieces and x-rays. On display will be the Galaxy chair mounted unit together with the latest J/V Generation chair with ultra-leather upholstery and Lumina light. Also on display will be the AXCS Drake suite with rear mounted unit

and Advantage suite together with AXCS chair and Faro light.

To meet the recent hazardous waste regulations DentalEZ offer the Ramvac Hg5 amalgam separator. Suitable for all wet line suction systems, it has 99.82\% mercury removal rate. The Star Dental range includes unique Solara and 430 series lube free handpieces, Starflex handpieces and Titan Plus scalers.

Reader response number 56

\section{International Dental Showcase 2005}

This year's International Dental Showcase is taking place at the NEC, Birmingham, on 6-8 October 2005. Organised by the British Dental Trade Association, dental professionals can take advantage of the latest in surgery and laboratory equipment and consumables from handpieces and operating chairs, furniture, units and cabinetry, to orthodontic and cross infection control products all under one roof at the exhibition. Product demonstrations, literature and service information will all be available on around 300 stands exhibiting the latest dental products and services hitting the dental world from companies from the UK, Switzerland, Italy, France, Holland and Japan.

Reader response number 57

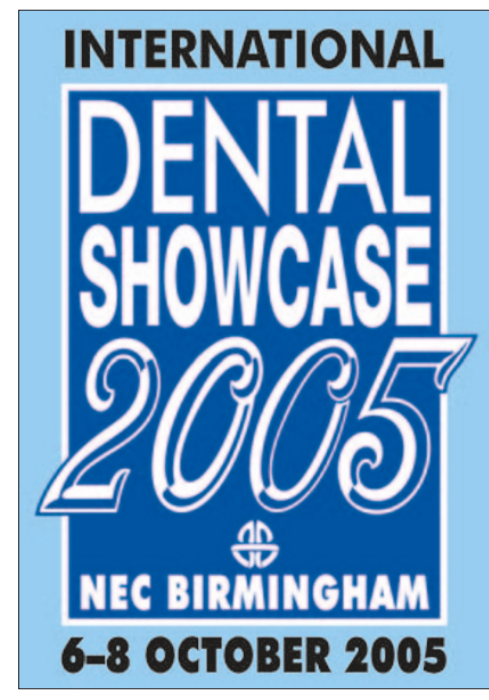




\section{New crown software}

New crown software from Cerec now makes the process of familiarisation with CAD/CAM technology even easier, enabling users to save time. In addition to inlays, onlays and veneers, it now provides dentists with the option of quickly constructing and manufacturing crowns at the chairside, providing patients with durable, aesthetic restorations in a single surgery visit. After the dentist has designed the crown on screen, the new software fully automates the process of fitting crowns to antagonists. With this development, Cerec imitates the teething process and provides design recommendations which are clinically exact. Its features include new automated occlusal adjustment to antagonist, new automated contact point adjustment, seven tooth databases and a reduced milling time. The Sirona team will be available on stand P15 throughout Showcase to demonstrate the new software upgrade.

Reader response number 58

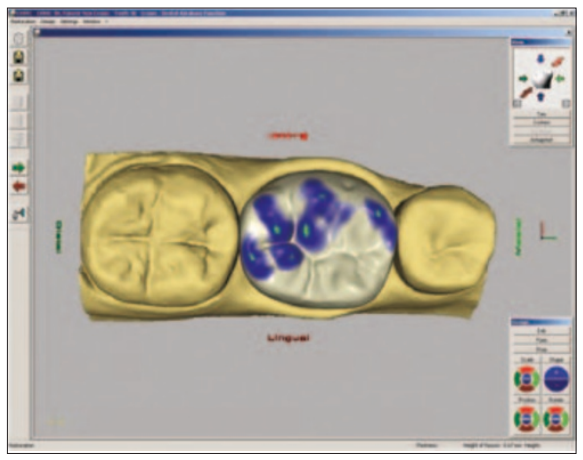

\section{Flowable microhybrid composite}

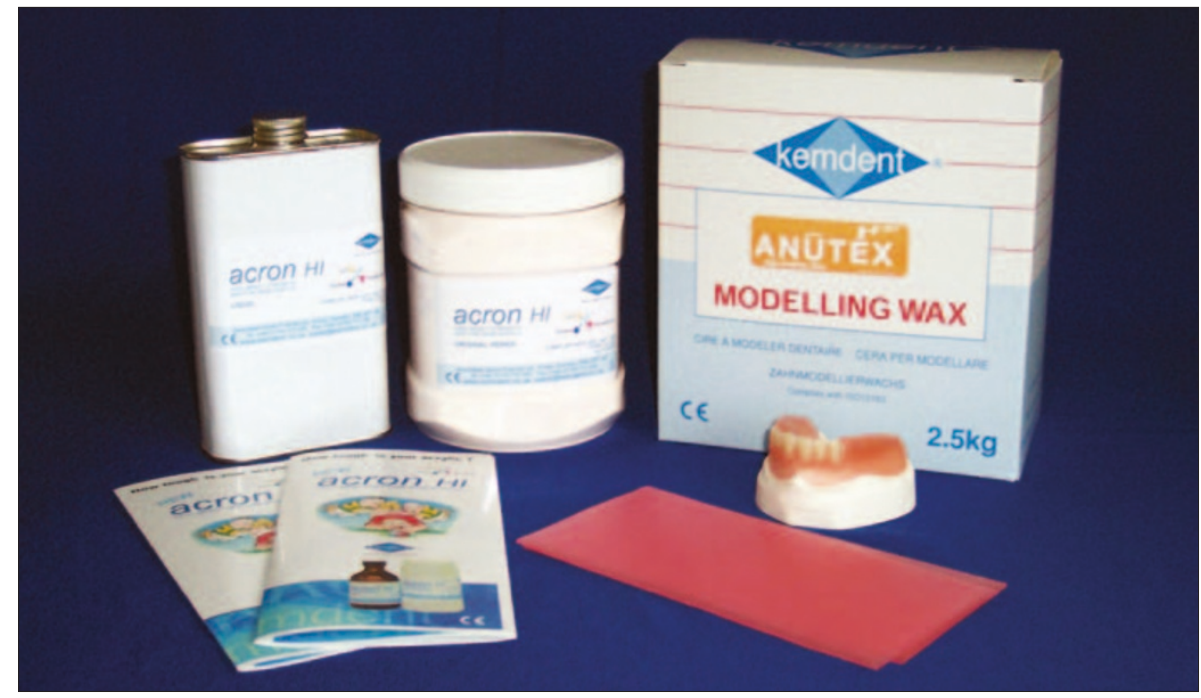

A number of new products will be on display at the Kemdent stand (B10) at this year's Showcase exhibition including the Diamond Finish restorative, an advanced, easy to use, microhybrid composite available in packable syringes and flowable application caps.

Light-curing, self-etching adhesive Diamond Bond uses the latest nano-technology bonding system. It enables dentists to combine the advantages of Diamond Carve GIC with the aesthetic benefits offered by Diamond Finish composite technology in a single procedure.

Also on the stand will be the new super strong Acron Hi acrylic and high stability modelling wax. The latest addition to Kemdent's range of acrylics it is a heat cure denture base acrylic designed for the manufacture of the highest quality full or partial dentures. Acron HI uses Kemdent's unique multi matrix technology to achieve the ideal combination of rigidity and resistance to breakage.

The product is available in a trial two unit pack, 250g and $1 \mathrm{~kg}$ packs and shades include original veined and light pink veined.

The new high stability modelling wax Anutex HS will also be on display. It has high temperature stability, a high gloss finish and is easy to fabricate. Visitors can take advantage of special 20\% discounts on Kemdent products at the show.

Reader response number 59

\section{Latest technology range}

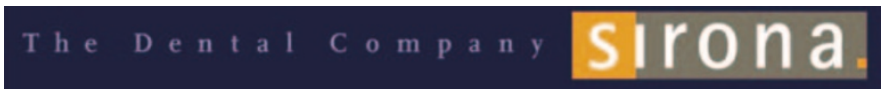

German manufacturer Sirona Dental Systems can be seen at through their general distributors, Henry Schein at stand E03, Minerva at stands M01/M02 and Sident Dental Systems stand E06.

The very latest in Sirona technology will be displayed and demonstrated. Formerly as Siemens and now as Sirona, the company manufactures products including treatment centres, both digital and conventional x-ray equipment, handpieces, patient communication products and Cerec ceramic restoration systems.

Reader response number 60

\section{Improving your posture}

DP Medical Systems Limited will be exhibiting the latest Global microscopes for dental microscopy on stand F07. The full range of Surgitel binocular loupes for correct and enhanced working position and improving posture to avoid stress, strain and long-term discomfort or injury will also be shown together with the latest innovations in image technology.

The DP Medical headlight video system with high quality optical and video components can also be seen at the exhibition. The system enables the user to share examination and operating procedures with third parties without any risk of disturbance.

Reader response number 62

\section{Popular instrument sets}

BDSI Ltd on stand P04 is a fast growing wholesaler specialising in handpieces, instruments and small equipment. There will be a range of popular instrument sets, ideal for setting up a new surgery, together with its own range of handpieces and motors on display. The latch type contra handpiece EC20L will be on offer in a buy five get one free promotion. For dentists considering a new vacuum autoclave, there is an offer on the new Prestige $\mathrm{C} 3$ advanced model with free printer and free instrument kit worth over $£ 700$. There will be other special show-only promotions available including the competitively priced new Prolux LED curing light available in three colours. Reader response number $\mathbf{6 1}$

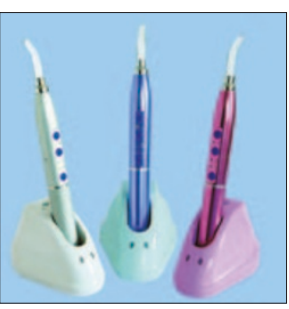




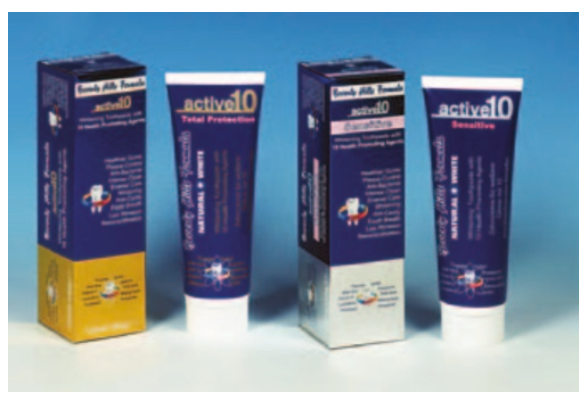

\section{New additions to range}

Beverly Hills Formula have launched the new Active 10 products range (available in two variants, Total Protection and Sensitive) to add to its existing range of tooth whitening toothpastes. As its name suggests, Active 10 is a unique formula that benefits from ten health promoting agents which not only protect teeth and gums and promote whitening, but also improve and maintain a healthy mouth. The toothpaste offers total protection, whitening and intense cleaning with plaque control, low abrasion, gum protection, enamel care and remineralisation. It also has an anti-inflammatory action, anti-cavity protection and promotes fresh breath.

Reader response number 66

\section{Design and functionality}

Sident Dental Systems at stand E06 will have a number of product innovations from Sirona on display. These include the Sirona C+ treatment centre which brings design and functionality, providing both maximum patient comfort and ergonomic treatment positioning. Full packages are affordable and offer value for money with low cost monthly finance packages. The Sirona Orthophos XG+ advanced X-ray unit is available as is Sidexis multi-purpose software (unlimited licenses) with information rich images and easy operation. The Mirroscope intraoral dental inspection mirror and camera will be on display. In addition, exclusively to Sident Dental Systems from Italy is Dental Art Furniture incorporating ergonomics, hygiene features and state-of-the-art functionality.

Reader response number 67

\section{New pre-dosed mixing capsule}

Amalgomer and Amalgomer CR were launched at the 2003 International Dental Showcase. The glass ionomer restoratives are able to exceed 300MPa compressive strength at 24 hours. At the 2005 Showcase Amalgomer and Amalgomer CR will be launched for the first time in a new pre-dosed mixing capsule. This presentation offers all the strength, durability and resilience of the hand mix version, but in a timesaving, easy to use format. All other properties are carried over from the hand mix material. Samples of the capsules will be available during the Showcase from stand N06.

Reader response number 63

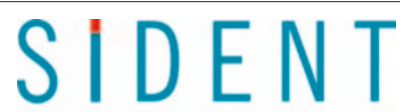

DENTAL SYSTEM S Now you're better equipped

CERAMIC SYSTEMS

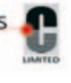

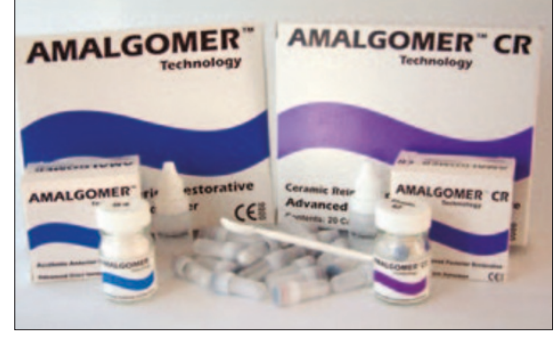




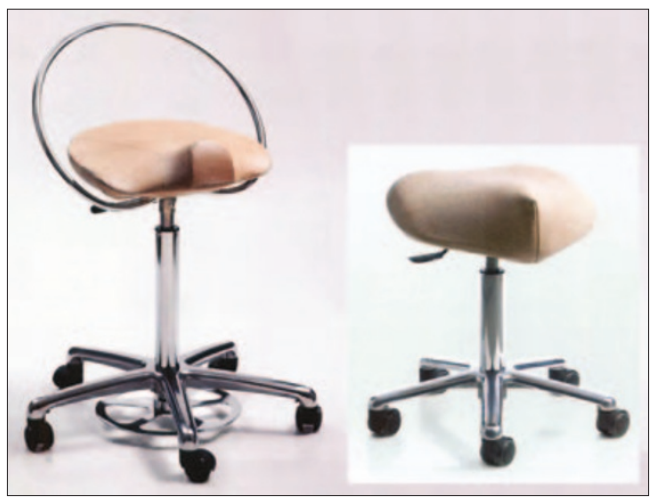

\section{Promoting better posture}

Greater comfort and improved posture feature strongly on Evident's stand at K01 and K02 this year. The new DynamoSeat and InCharge stools actively promote better posture for the whole dental team by encouraging a correct sitting position with greater levels of comfort. While seated, backs can be upright and better balanced, legs are also less restricted offering improved circulatory benefits and greater mobility around the surgery.

The Orascoptic loupes offer a full range of lightweight and stylish magnification options with a consistently high-resolution quality image and will be available to try. The 'silent-running' Zeon Illuminator provides perfect illumination to enhance the magnification experience while the Twist, a disposable reciprocating prophy angle along with the Danville range of air abrasion units and dust cabinets for patient and laboratory use will also be on display.

Reader response number 64

\section{Perfect spinal balance}

The Bambach Saddle Seat was recently launched in the UK and is now sold in over 62 countries. The chair also helps maintain natural spinal curves, reduces neck, shoulder and back pain and encourages upright posture. It is shaped like a horse's saddle and uses the biomechanics of the body to naturally position the spine while supporting the pelvis, promoting perfect spinal balance. The ideal seated posture is with legs positioned at around 45 degrees which ensures muscles at the front and back of the body are balanced and the body's centre of gravity is over the supporting base rather than behind. This position relieves and prevents back pain, while also giving complete mobility for seated work.

The idea for the saddle seat first surfaced in 1978 when its designer, Mary Gale, an occupational therapist from Australia, used horse riding as method of rehabilitation for patients, many of whom were seriously disabled.

Reader response number 65

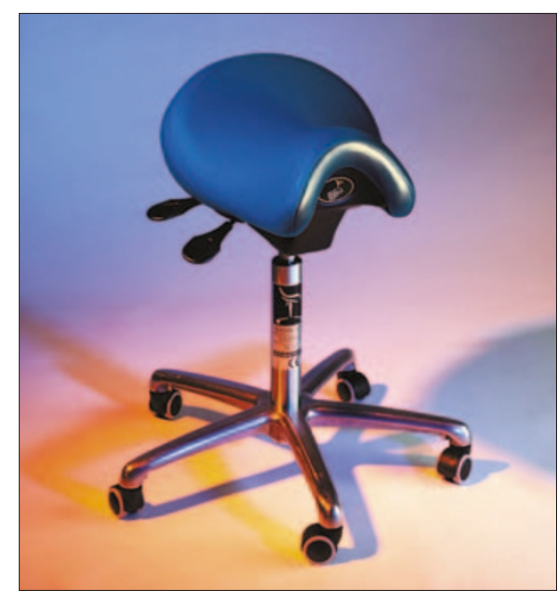




\section{Tissue management treatment systems}

Velopex are showing their very latest Aquacut unit at this year's exhibition. It combines the abilities of a conventional 3-in-1 syringe with the cutting abilities of the Aquacut Fluid Abrasion system, resulting in a system that can stay in your hand from polishing, drying, cutting or etching to washing. Velopex are also showing the Diode Laser with its gentle and predictable results in soft tissue management. The unit delivers abilities with perio and endo as well as the ability to do tooth whitening.

The treatment systems can be used for tissue management and are very patient friendly and visitors are invited to come and find out how they can help with building a modern dental practice.

The company are also showing the very latest machines and accessories in their wide range of diagnostic products. With its new generation of $\mathrm{x}$-ray film processors come high quality film, processing chemicals and a wide range of x-ray viewers. Also showing is the Vischeck Quality Manager for precision control of processor output, and its convenient new processor cleaning tablets.

Reader response number 68

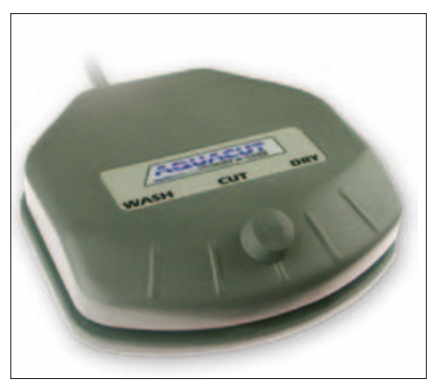

\section{Dental treatment centres}

Clesta II, Takara Belmont's new dental treatment centre, makes its UK public debut at Showcase. Visitors to the Takara Belmont stand at M05 will have first-hand experience of the new range of treatment centres in either over-the-patient, holder or Continental rod type, cabinet or mobile cart configurations.

An evolution of the Clesta, Clesta II incorporates many refinements and detail improvements offering style combined with comfort, ease of use and flexibility. It is available in right or left-handed format allowing operators to create their ideal working environment and will accommodate all future regulations. The ergonomic cuspidor housing is designed with forthcoming amalgam separation in mind, so there is sufficient space to install additional equipment. For extra peace of mind the Clesta II is also covered by the standard Belmont extended warranty. Also on display will be the new Phot-X II, a multi function DC x-ray machine which allows reduced skin dosage with optimum radiation

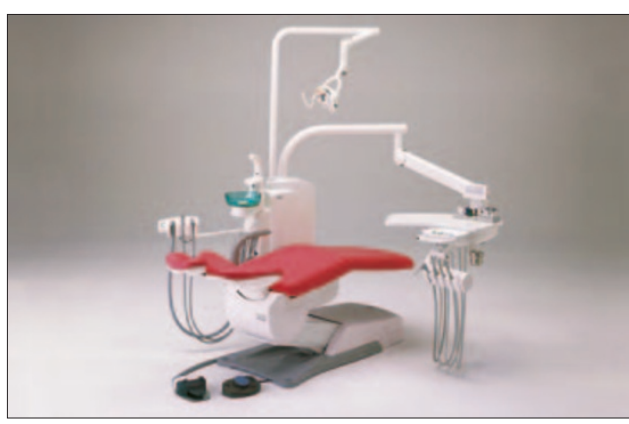
levels for every diagnostic need. The minimum exposure time is 0.01 seconds and it is compatible with any type of digital imaging system with an easy to position, compact head. The stand will also feature the popular SP Cleo Treatment Centre with its unique 'folding leg rest' allowing easy access for patients, together with the flexible Voyager IIL for both left and right handed dentistry.

Reader response number 69

\section{New look for irrigator}

Mirage Dental will unveil a new look for the Kitty Waterjet at the exhibition which has now evolved to become the Kitty Hydrofloss. The Kitty Hydrofloss is an oral irrigator and while cosmetically there have been a number of improvements, the major change from the Waterjet is the magnetic handle.

Also on display on stand L16 will be the Floss \& Brush. It is designed specifically for cleaning small interdental spaces, as well as massaging the vulnerable space between tooth and gum. Particularly good for patients with appliances, it is built to manoeuvre around them.

The tip tapers to $0.5 \mathrm{~mm}$ to give easy access to most interdental spaces and floss is woven onto a fine mesh and moulded onto an easy grip handle. The floss expands to fill each space to efficiently remove plaque in just a few strokes.

The large round headed, short firm-bristled Original Tung-Brush reaches easily into tongue crevices and the patented design minimises the potential for gagging while the water-based Tung-Gel, formulated with zinc, creates a fresh feeling which lasts well into the day.

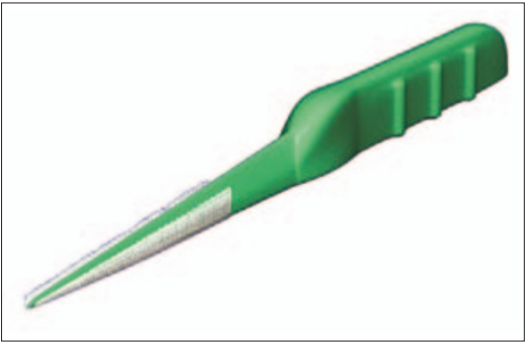




\section{Range of product solutions}

Septodont stand at A06 will show a number of product solutions to all aspects of clinical dentistry which will be demonstrated at Showcase. Septocalm is a quick, painless and effective treatment solution for the common mouth ulcer, or canker sore which cauterises on contact eliminating the herpes type virus and easing the discomfort.

Septodont's range of injectable anaesthetics, Septanest (articaine), Scandonest, (mepivacaine), and the dental standard, Lignospan (lidocaine), plus surface anaesthetics Xylonor gel and spray will also be available.

A clinical solutions chart in an easy to carry format containing 118 product solutions for clinical problems will be available together with a complimentary bag of chocolate gold coins. This year Septodont are running two daily prize draws. Visitors can leave their business card or a compliment slip at the stand and could win a Locapex 4000 apex locator or an ipod shuffle.

Reader response number 71

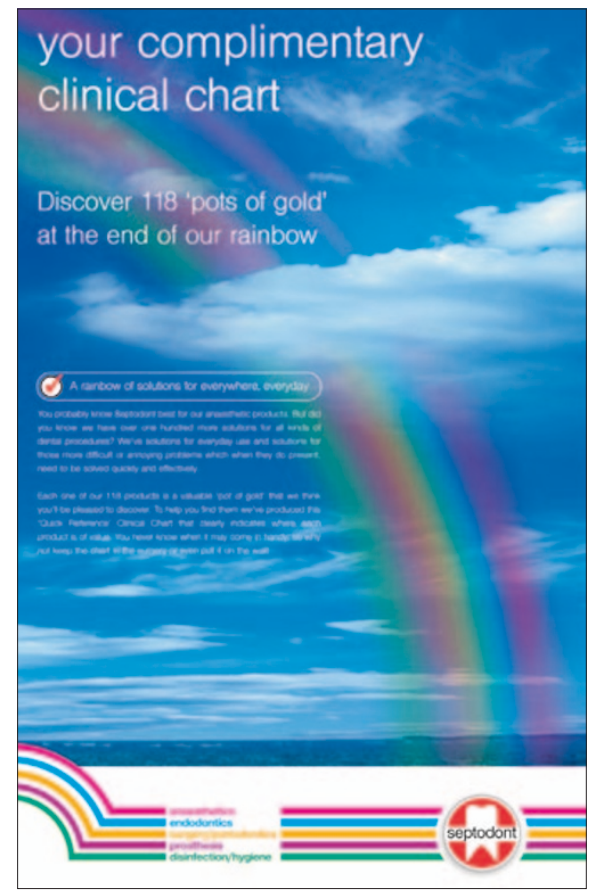

\section{Mobile dental treatment unit}

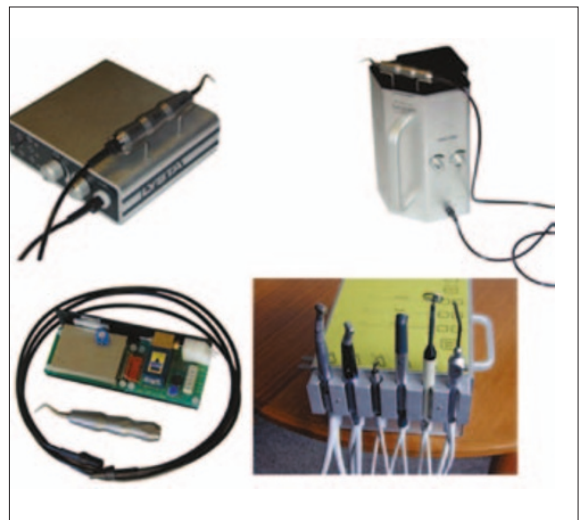

Visitors to Lysta's stand M11 at this year's exhibition can see the PortaDent - the new, electronically-controlled, mobile dental and dental hygiene treatment unit.

Available in three different models, the PortaDent makes dental treatment accessible to patients in every corner of the world. If mains power is not available, the units can be battery operated. The mobile units take into consideration all aspects of dental care, including infection control and are characterised by smooth, easy to clean and disinfect surfaces. Other features include an oil-free compressor, a keyboard for selection and adjustment of all features, electronic controls and instrument detectors, cordless foot control and an internal mini-suction for saliva.

Reader response number 72

\section{Accurate shading}

Kerr will be demonstrating a selection of products at Showcase this year. This includes composite restorative material, Premise. It contains three different filler sizes to optimise polish, handling and strength and to reduce polymerisation shrinkage.

The Demetron Shade Light replicates ideal lighting conditions. The portable unit fits comfortably into the palm of your hand and influencing external colours are blocked out. Simply switch the light on and accurately choose the shade that best matches the patient's dentition. The shade light can be used for all restorative shade matching procedures.

Maxcem self-etch, self-adhering resin cement provides good bond and mechanical strengths, aesthetics and simplicity as the system allows all the essential ingredients to etch, prime, bond and cement to be combined into one product.

The company's new Sterile Kit contains a tray with disposable instruments including a stainless steel explorer probe, tweezers and mirror, patient bib, a napkin, two cotton wool

rolls and two latex-free 'ear loop' masks. It can be used for busy days, staff shortages, high risk patients and domiciliary visits. Reader response number 73 


\section{Independent financial planning}

Specialist in independent financial planning MLP Private Finance can provide holistic financial advice, which includes residential and buy-to-let mortgages, commercial mortgages and practice finance, retirement planning, inheritance tax planning and protection. All of the consultants attending the showcase on stand C11 and L0 are part of the Dental Branch of MLP. The company is also offering visitors the chance to win a short break to a European destination of their choice by entering into its free draw.

Reader response number 74

\section{Instantly accessible records}

Visitors to the Clearview dental products stand (S08) will be offered a special two-forone promotion on Clearview x-ray mounts. The mounts provide a unique way of not only viewing patient $\mathrm{x}$-rays quickly and accurately, but also provide a medium for indexing/ filing as the green coloured borders are easy to write on. Patients' records are instantly accessible in a handy, hygienic wipe clean mount which can then be securely placed back in the notes for safe future reference.

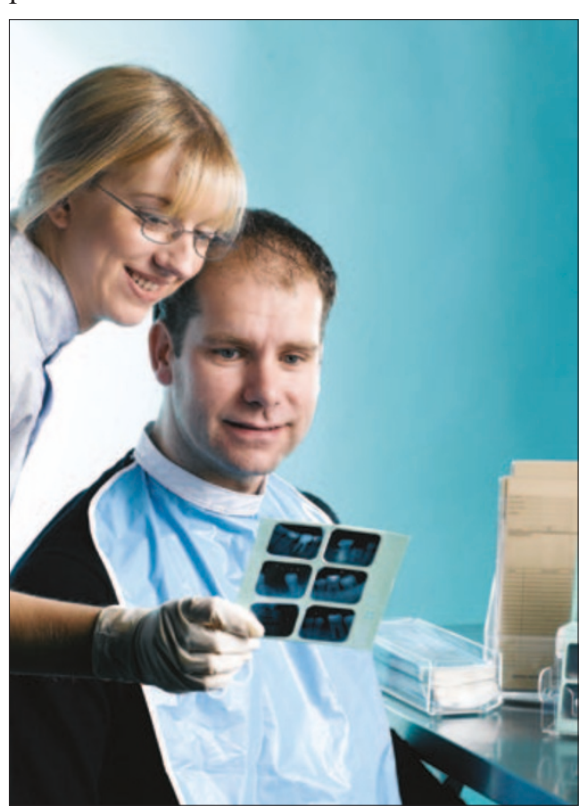

They are available in four versions: CV6 holds three sets of bitewings or six periapicals and CV16BW holds 16 intra-oral x-rays in sets of two with space to label each or eight sets of bitewings. CV16FM holds 16 Intra-oral $\mathrm{x}$-rays in 'Full Mouth' pattern, ideal for periodontal and restorative procedures whilst CVO holds single occlusal $\mathrm{x}$ rays with a useful labelling space.

The range also includes a practical array of draw tidies for neatly storing anything from needles to impression trays, clear plastic wallets for patient record cards, patient record card stands, organisers and economy clear plastic mixing pads.

Also available on the stand will be the new range of Zeffiro hand instruments with patented smooth handle to fight cross infection control and there will be a the special low cost introductory diagnostic kit offer.

Reader response number 75

\section{In-depth analysis}

Denplan will be running a series of free Insight seminars at Showcase, providing analysis of the NHS reforms and what they hold in store for practitioners. The company will also be formally launching its 'fast track' conversion programme at the event. For those dentists wishing to establish a list outside the NHS before the new contract is introduced, fast track enables them to move into private practice with Denplan in a matter of weeks. There will also be a number of seminars throughout the show for dentists wishing to find out more about Plans for Children introduced by Denplan in response to dentists' concerns about how they will fund their child patient care in the future. These seminars will give an overview of Plans for Children and how they could be implemented into individual dental practices. To find out times and details of the seminars visit the Denplan stand (E4).

Reader response number 76

\section{Orthodontic range}

TOC on stand F01 are suppliers of orthodontic materials and also offer many products in other dental specialities. Visitors to its stand can see the Easy-Vac Machine demonstrated, which is a streamlined vacuum forming machine that can be used for constructing bleaching trays, mouthguards, nightguards as well as orthodontic retainers.

TOC will also be showing System 'R', a ligature free bracket which can reduce treatment time significantly as well as the new ceramic bracket from GAC - Interactive Mystique with Neo-Clip works in conjunction with Mystique's glazed slot to produce a treatment time is as fast as traditional metal brackets. The company's range of oral care products including their unique oral hygiene kits which are suitable for all patients will also be available.

Reader response number 77 